Krystyna Droździał-Szelest

Uniwersytet im. Adama Mickiewicza w Poznaniu

krysiad@wa.amu.edu.pl

Mirosława Anna Domińska

Uniwersytet im. Adama Mickiewicza w Poznaniu

dominska@amu.edu.pl

\title{
DEVELOPING WRITING STRATEGIES OF POOR LANGUAGE LEARNERS AT THE LEVEL OF JUNIOR-HIGH SCHOOL
}

\begin{abstract}
Although language learning strategy research has been going on for almost forty years and has provided both theorists and practitioners with an abundant body of knowledge on the subject, there are still areas that need further investigation. One such area is the use of strategies in language skills development, with the skill of writing being singled out as deserving special attention. It is suggested that in order to better understand the processes involved, we need more information concerning the development of the skill by learners, as well as more data revealing the effects of strategy based instruction, especially with reference to children and adolescents in different foreign language learning contexts.

Hence, this article makes an attempt to contribute to the ongoing discussion by focusing on a special group of learners - poor language learners, at a risk of educational failure - who are learning a foreign language (English) in the context of junior high school. The article consists of two parts: its theoretical sections focus on some issues related to poor language learners, with emphasis on factors impacting their school problems in general and learning of the writing skill in particular. Then, based on the literature review, some research findings concerning writing strategies and the effects of strategic training are discussed. The second part presents and comments on the data obtained during the course of an informal study carried
\end{abstract}


out in a junior high school within the framework of an educational project which was remedial in character.

Keywords: language learning strategies, poor language learners, strategy based instruction, writing in a foreign language

Słowa kluczowe: pisanie w języku obcym, słabi uczniowie (w odniesieniu do uczenia się języka), strategie uczenia się języka, trening strategiczny (trening w zakresie strategii)

\section{Introduction}

In spite of the abundance of research studies carried out on language learning strategies in different learning contexts since the late 1970's, researchers point to the fact that there are still important areas that need further exploration. Among such areas are how students develop language and learning or study skills, the influence of which on achievement in the context of language skills is still undervalued, if not ignored by teachers. Hence, the aim of this article is to contribute to the ongoing discussion by presenting findings from an informal study focusing on learners whose underdevelopment or lack of relevant learning/study skills qualifies them as poor learners not only in terms of language learning, but also in terms of general education. The study aimed to identify strategies used by these learners to develop their writing ability in English and compare them with strategies used by more successful language learners. It also attempted to consider to what extent the learners would be able to improve or modify their learning skills as a result of strategy based instruction.

Writing is a skill which is considered difficult to acquire even in one's native language, thus it comes as no surprise that learning to write in a new language can be an extremely frustrating, time consuming process which, in addition, requires a lot of effort. As it is not often regarded as a high priority in language classrooms, it is necessary for learners to be aware of their writing needs in the foreign language, in order to be able to develop the skill by themselves. More significantly, learners (and teachers as well) need to realise that there is a difference between writing to learn the language and learning to communicate in writing, with the latter gaining in importance in the globalized world. It seems that for learners at a lower level of language proficiency, especially 'poor language learners', it will probably be more practical to focus on writing as a support skill, both in and out of the language classroom. Perceived in such a way, writing becomes a tool which helps to consolidate learning of other skills and language components; it may be used, for instance, to support 
the learning of grammar and vocabulary or as a preparation for a speaking activity. In short, it is crucial, especially for poor language learners, to become aware that writing is a "good thing" in language learning for a variety of reasons, the most important perhaps being that it allows conscious development of the language which is indispensable in becoming a successful language learner. ${ }^{1}$

According to Rubin and Thompson (1994: 110), "if you are a good writer, you will probably be a good writer in a foreign language once your language proficiency allows you to deal with ideas freely". They believe that most learners are capable of recognizing strategies that helped them write well in the native language and of transferring them to the foreign language learning context. It seems, however, that such an assumption may be over-optimistic, if not unfounded, when we deal with poor language learners.

It often happens that when labelling students 'poor language learners' teachers tend to overlook the fact that such students typically experience problems with school learning in general, and that the problems in question can be generated by a number of different factors, with "learner attitudes and approaches" foremost as far as levels of achievement are concerned (cf. Cottrell, 2001: 29-35). It is vagueness about the object of learning, among other things, that is perceived as decisive. This refers to the fact that learners are neither aware of the goals of learning a particular school subject or skill, such as learning a foreign language, nor do they perceive its purpose and significance, as is often the case with learning to write in a foreign language. Equally important, especially among adolescents, may be "their fears of disclosing difficulties", because, for instance, other students may find out that they need help and thus ridicule and reject them, or teachers may have poor opinion of them as a result of their lack of progress and/or poor performance in class (e.g. not being able to write). Another problem will be anxiety about 'not being good enough' (such as not being good at current performance in writing in comparison to other, more able peers), which will, undoubtedly, contribute to the students low self-esteem related to their cognitive/intellectual capacities and may result in loss of motivation to learn. It is also quite common that students do not know how to evaluate their own performance, i.e. they lack self-evaluation abilities. Finally, often students are attached to inefficient strategies, which results from their not being aware of own learning styles or strategies that would be most useful. Having no relevant knowledge, they

\footnotetext{
${ }^{1}$ On the other hand, writing as communication plays an important role as well, as, among other things, it lets learners express their personalities and, perhaps more importantly, is valuable in itself as learners may derive satisfaction just from having something written on their own (cf. Harmer, 1998: 79) which, in turn, may contribute to their overall confidence.
} 
stick to the "ways" they feel safe with, which in turn inhibits their language learning (c.f. Cottrell, 2001: 29-35).

Thus, the question arises whether it is possible to help such learners to overcome their problems and provide them with tools which, when deployed in a skillful way, will contribute to higher levels of achievement not only in language learning, but also in different areas of school education. The answer to this question seems to be the development of relevant skills and strategies.

In Cottrell's words, "skills refer to the quality of performance which is developed through practice, training and experience" and "to be skilled is to be able to perform a learned activity well and at will" (2001: 9). As far as language learning is concerned, Cohen (2011: 17) explains, that "skills" mean the ability to do something and strategies "are the means to operationalize a skill". Thus, referring to skills-based approach, he views strategies "in terms of their role in operationalizing both the receptive skills of listening and reading, and the productive skills of speaking and writing". In his opinion, strategies are needed in the language learning process for the following reasons:

1. To enhance learning;

2. To perform specific tasks;

3. To solve specific problems;

4. To make learning easier, faster, and more enjoyable;

5. To compensate for a deficit in language proficiency (cf. Cohen, 2011: 29-31).

In the section below the most important findings from writing strategies research will be discussed to support the above claims.

\section{Literature review - research on writing strategies}

Even though the number of studies on learning to write in a foreign language and the effects of instruction on the development of writing ability is rather scant in comparison with research on other language skills and areas, their findings are important in arriving at a better understanding of how language learners use strategies and what can be done to support them in their endeavors to become more successful language learners.

When it comes to poor language learners, some earlier studies investigating the use of language learning strategies (see, for instance, Vann and Abraham, 1990; Wenden, 1991, 2001; O'Malley and Chamot, 1990; Oxford, 2008) were of significance in identifying differences between "good" and "poor" language learners. They revealed that more effective language learners deployed a greater variety of strategies, which they used more often; in addition, they proved to be better at identifying problems with learning and using the language, as well as talking about them (cf. O'Malley and Chamot, 
1990: 143). On the other hand, as Oxford (2008: 51) notes, "less proficient learners often use strategies in a desperate way, not knowing how to identify the needed strategies". Poor language learners in Vann and Abraham's study were found to have problems with choosing strategies appropriate to the task at hand and, in the words of the researchers, "apparently, (...) lacked certain higher-order processes, what are often called metacognitive strategies or self-regulatory skills, which would enable them to assess the task and bring to bear the necessary strategies for its completion" (1990:191).

Thus, to sum up, it is metacognitive knowledge, defined as "that part of our long-term memory that contains what learners know about learning", which is decisive in differentiating between successful and poor learners, and can be considered the key to effective learning, and hence, performance in a foreign language classroom (c.f. Wenden, 2001: 44-45) ${ }^{2}$. Metacognitive knowledge is also believed to be critical to the self-regulation of learning ${ }^{3}$; in other words there exists a strong relationship between what learners know about language learning and their approach to the task at hand. Research conducted in different educational contexts provides convincing evidence that it is possible to change the effectiveness with which students learn. According to Miller (1996: 19), "developing study skills in school and college students can have dramatic effects on their academic achievement", especially as very often poor performance in class can be attributed to the wrong approach to the task on the part of the students, or no approach at all, and not because of a lack of ability as such. He is of the opinion that "by introducing students to strategy training it is possible to make them re-think the aims of study" and introduce to them more efficient and interesting ways of learning, giving them at the same time "a sense of mastery over their study situations" (ibid.). The results include an increase in their confidence as well as a desire to face new challenges.

Cottrell also supports the idea that training students in relevant study skills will result in improvement in areas such as attitude to learning, strategy use, flexibility as far as the context of learning is concerned, thinking skills or metacognition in general, and awareness or rather "our meta-awareness of ourselves as learners" (2001: 45-46). Additionally, she emphasizes the role of "personal qualities", such as "motivation, commitment, awareness of what is

\footnotetext{
${ }^{2}$ According to Wenden (2001: 46), from the point of view of effective learning, three types of metacognitive knowledge are distinguished: person, task, and strategic knowledge, focusing on, respectively, learner, task, or process variables.

${ }^{3}$ Self-regulation "refers to the processes by which learners plan how they will approach a task, their task analysis, and how they actually monitor its implementation" (Wenden 2001: 50); it is also known as self-direction.
} 
required, perseverance, and the ability to manage set-backs" and draws attention to the fact that students benefit from explicit teaching focusing on reflecting on practice, learning to learn, applying learning to new contexts, etc., all of which contribute to improving one's performance (Cottrell, 2001: 9).

A similar stance is taken by Anderson (2008: 104) who claims that "rather than focusing learner attention only on language issues, educators can structure a learning atmosphere where thinking about what happens in the learning process will lead to stronger language skills". Among the tools to develop metacognition, he lists language learning surveys and questionnaires, group evaluation forms, and self-assessment on classroom tasks (cf. ibid.: 105-107).

In her review of different studies on writing strategies, Chamot (2001: 32) confirms that differences between more and less effective writers were found in the number and range of strategies used, how these were applied, and whether they were appropriate for the task. As she explains, in the studies reported, "students' understanding of the tasks' requirements and whether they could match a strategy to meet the requirements seemed to be a major determinant of effective strategy use". These were good language learners (writers) who proved skillful at matching strategies to the task they were working on, while the less successful learners seemed to lack metacognitive knowledge about the task requirements needed to select appropriate strategies. Chamot found this trend to be consistent among different age groups (children, high school students, and adult language learners) and in both ESL and EFL contexts.

Metacognitive strategies were found to be important in other studies of writing strategies as well. For instance, Bloom found that even though the students most frequently used cognitive strategies, "those students who used both cognitive and metacognitive strategies in their L2 writing were able to outperform those who used cognitive strategies alone, supporting the claim that learners with control over a wider range of strategies will be more successful" (2008: 106-107).

Other findings indicate that language learners/writers use a wide range of strategies in an attempt to learn to write and to communicate in writing and that their "strategic behavior" depends on a variety of factors. For instance, it was found that choice and use of strategies was influenced by the learners' literacy in their first and/or second language as well as their educational experience, with their perception of the usefulness of strategies playing an important role (cf. Manchón et al., 2007). In terms of strategy use, Bloom (2008: 112) notes that learners treat the first language as an important problem-solving device and use it consciously when they need to understand the assignment, to plan content and organization of their writing, to monitor, to translate "key words and phrases", etc. She believes, however, that no matter 
how useful this strategy may seem to the students, in the long run, overreliance on or overuse of it, may have some "undesirable side-effect" on second/foreign language writing.

As a result of research focusing on writing strategies deployed by foreign language learners, researchers have produced a list of "good writers" strategies, which might be of use when planning strategy training for less effective learners. According to Gordon (2008: 248-251), the following behaviours (here understood as equivalent to strategies) are characteristic of such learners:

1. Good writers read

2. Good writers attend to vocabulary

3. Good writers develop strategies to manage a degree of uncertainty

4. Good writers attend to meaning

5. Good writers attend to grammar

6. Good writers work on their writing until it effectively responds to the set task and the ideas expressed are clear and coherent

7. Good writers actively generate their own interest to write

8. Good writers create opportunities to write outside the classroom.

As regards the effects of strategic instruction, there seems to be general consensus among researchers that learners benefit from such interventions. The strategic behaviour of "writers" changes as a result of the instruction received in class; in other words it can be modified through strategy training (cf. Manchón et al., 2007; Cohen, 2011). For instance, the data revealed the positive influence of instruction on students' approaches towards writing tasks and their development of confidence and autonomy which affected the quality of their essays in a positive way. It was emphasized, however, that the duration of the programme was crucial, as long programmes seem to produce better outcomes in terms of writing; in other words it is necessary for the students to engage in as much writing practice as possible (cf. Manchón et al., 2007: 247).

Intervention studies confirm the importance of a metacognitive component; as Cohen (2011: 179) comments, “(...) an intervention featuring metacognitive strategy instruction may enhance writing performance if the learners have the requisite skills to benefit from the intervention and if they are motivated to do so". On the basis of the review of numerous studies he suggests, for instance, that "a focus on revision strategies in writing can contribute to student writers' ability to think more globally" (ibid.).

Evidence supporting the claim that students can learn to use strategies and that the use of instructed strategies results in more effective learning and school achievement also comes from learning strategy instruction studies in native language (cf. Chamot 2001). It seems to be of particular importance 
that “(...) improvement in writing performance has been reported in several studies in which learning disabled students were explicitly taught strategies for planning, composing and revising their writing" (Chamot, 2001: 28). Furthermore, it turned out that "limited English proficiency children taught brainstorming and clustering strategies produced significantly more elaborations in their essays and their paragraphs were better organized" (ibid.: 37).

As for other findings, researchers point to proficiency level as a crucial variable. The learners' degree of writing expertise, which accounts for differences between more and less competent writers, is decisive when it comes to the qualitative/quantitative use of strategies and the effect a strategy may have. Another critical factor seems to be the learners' (=writers') mental model of writing, ie. the conceptions and beliefs that underlie and guide their writing performance. Some important differences between more and lessskilled writers were found here, with more-skilled learners perceiving writing as a multi-dimensional process, and less-skilled following a grammar driven model, in which they focus on individual sentences rather than the construction of a whole text/discourse (cf. Manchón et al., 2007: 244).

Summing up the above discussion, it can be said that "(...) systematic instruction and practice with language learning strategies is needed for many students in order to learn how to apply strategies effectively" (Chamot, 2001: 37). It is also true, though that some students are able to acquire effective learning strategies without instruction.

\section{The study}

The data presented and discussed in this article come from an informal study conducted within the framework of a broader educational project of a remedial nature ${ }^{4}$, whose aim was to help underachieving junior high-school students boost confidence and improve their overall school performance. The students, first and second graders, aged 14-16, were diagnosed as being at the risk of educational failure due to learning/study problems and "poor grades". The original project, which was carried out in one of the junior high schools in a small provincial town near Łódź, encompassed all the school subjects and its participants were selected by their class tutors and subject teachers after consulting the school psychologist. The major criterion were low grades which identified the students as poor language learners.

The "English part" of the project involved students of English philology - teacher trainees from Adam Mickiewicz University - whose task was to help

${ }^{4}$ Comenius Regio Project No. 2011-GB1-COM13-10911-2. 
poor language learners improve their performance in English through providing them with remedial treatment which spanned a period of two school years and consisted of additional 60 hours of classes combined with two learning strategy training sessions. The project was not research-based, hence it can be said that the data obtained in the process constitute an added value or are a by-product of the whole venture. The main source of data were three questionnaires administered to the students before, during, and after the course of the treatment. Other procedures involved informal individual and group interviews with students and teacher-trainees as well as participant observation.

During the first year of the project there were 38 participants -22 first graders ( 18 boys and 4 girls) and 16 second graders ( 12 boys and 4 girls). During the second year, 36 students participated in the project -22 second graders (the former grade 1 ) and 14 third graders (11 boys and 3 girls, former grade 2 ).

Since special attention was given to the strategies deployed by the learners to cope with the development and improvement of language skills and vocabulary, at the very onset of the project they were invited to fill in a questionnaire whose purpose was twofold: to obtain information necessary for the preparation of a remedial programme addressing their actual needs in learning English as a foreign language and to gather data indispensable for assessing the effectiveness of strategy based instruction.

As has already been explained, the major focus of this article are strategies used by poor language learners to develop the skill of writing whose value, as argued in the theoretical sections, is often underestimated by the students. Because they are not aware of its role and purpose in the process of learning the language, they do not feel the need to write in English, to say the least. Hence, students were asked how they assessed their ability to write in English or what they did/how they tried to improve their writing - for instance, how they worked on making their descriptions better. There were questions about the way they dealt with written tasks in English, that is whether their approach to those tasks was similar to or different from the approach they adopted when dealing with written tasks in Polish. The students were asked similar questions after the first strategy training session (towards the end of the school year) and, then the following year, after the second strategy training session. Additionally, after each training session they were asked to indicate strategies that they had become familiar with during their English classes (from the training manual). The rationale behind this procedure was to make the strategies explicit to the students so that they could consciously refer to them when talking about their learning process.

The strategy training was conducted in the following order:

- Familiarizing students with different learning styles 
- Helping students recognize their own learning styles

- Eliciting from students techniques to learn/improve their writing

- Familiarizing students with different ways to learn how to write

- Analyzing learning/teaching materials and showing students how they can use them for self-study in order to improve their writing

- Developing the ability to use techniques aimed at improving writing

- Assigning tasks enabling students to make use of the self-study techniques they were taught

- Summing up: reflection on how students managed to complete the task at hand; which of the techniques they used to complete the exercise; how successful they were.

Familiarizing students with different learning styles was explicit in form; they were provided with a description and then an explanation of how different styles work and later asked to fill in a questionnaire which allowed them to identify their own learning style profiles. Other activities included discussions about learning, brainstorming and feedback from the teacher. Coursebooks and other lesson-related materials were used to acquaint students with various techniques for learning to write and self-study to improve their writing. Both teacher feedback and self-assessment techniques were used to evaluate students' performance on written tasks. The materials used for the purpose included, among others, a Polish version of Learning My Way. A Handbook on Language Learning Strategies (2003) and Learning to Learn English. A Course in Learner Training (1989), as well as the students' regular coursebooks - New Exam Connections 2 and 3, and Longman Repetytorium Gimnazjalne.

Although the major purpose of the first questionnaire was to obtain information necessary to plan a course which was suited to the students' actual language learning needs, it also allowed some insights into their "ways" of learning to write. As the students in question had various problems and lacked interest in learning, the list they produced was not particularly impressive (cf. Fig. 1 below). 52\% were not able to name any particular technique they used to develop their writing ability; while four (4) strategies were indicated in the remaining answers: $19 \%$ of the respondents claimed to use a dictionary; $15 \%$ stated they used additional materials to find relevant vocabulary, $7 \%$ asked other people for help; and the same percentage (7\%) claimed they tried to write a lot in English. Their answers can be described as rather vague, which corresponds with research findings that poor learners have problems with reflecting on and reporting on/talking about how they learn. 


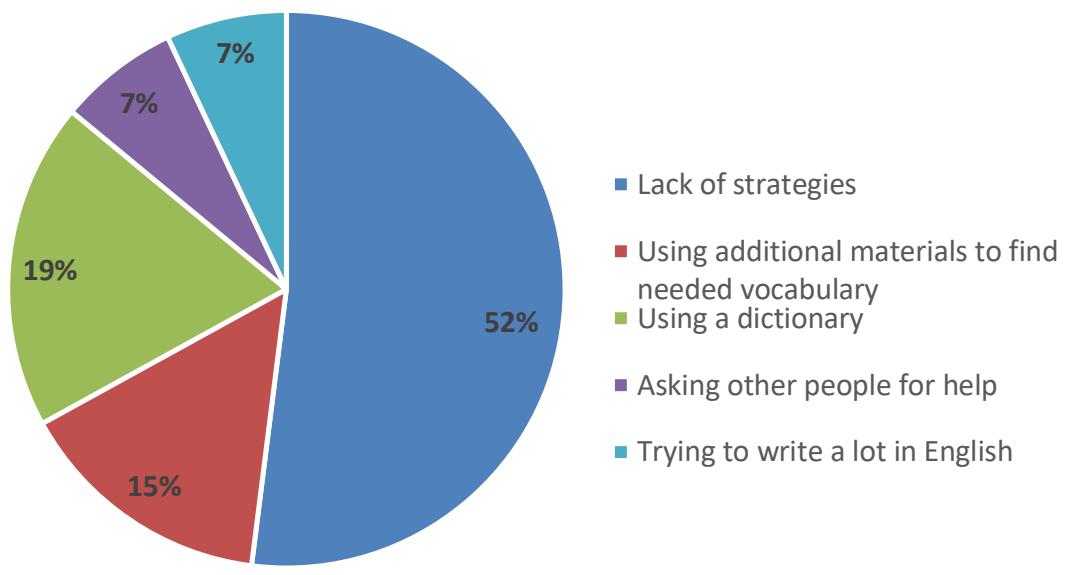

Fig. 1: Reported strategy use (writing) before the first strategy training session.

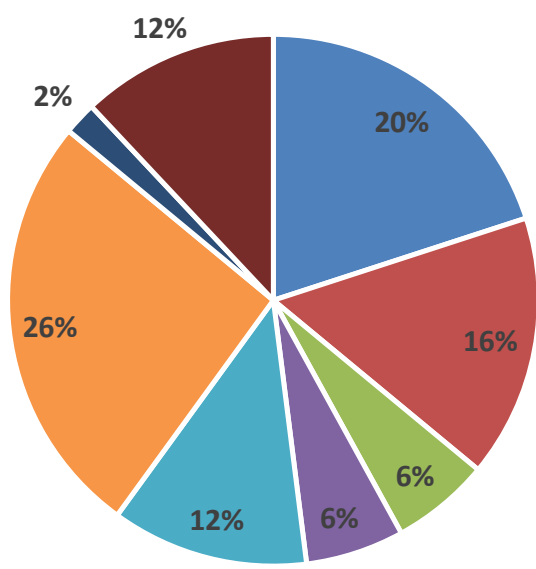

- Lack of strategies

- Learning new words and expressions

- Using a dictionary

- Asking other people for help

Writing based on a model text

- Trying to write a lot in English

- Replacing unknown words with familiar ones

- Self-correcting

Fig. 2: Strategy use declared by the students after the first training session.

However, the same question asked sometime after the first training session generated more varied responses. As it can be seen in Figure 2, the range of strategies reported by the students, although still very modest, is somewhat wider. First and foremost, there were fewer students who were not able to identify any strategies ( $20 \%$ vs. $52 \%$ at the onset of the project). The same tendency appeared as far as the use of a dictionary (6\% vs. $19 \%$ ) and asking other people for help are concerned, although in the latter case the difference 
is negligible ( $6 \%$ vs. $7 \%$ ). More students seemed to take to trying to write a lot in English - 26\% in comparison with the declared 7\% before the onset of the project. What is significant, though, is the emergence of new strategies: learning new words and expressions (reported by $16 \%$ of the respondents), writing based on a model text (12\%); self-correcting (12\%), and replacing unknown words with familiar ones (2\%). One strategy mentioned previously by $15 \%$ of the respondents, namely using additional materials to find the relevant vocabulary, was not among the strategies declared on this occasion.

Towards the end of the project, after the second strategy training session, however, some unexpected changes took place, as illustrated in Figure 3 below. Although the number of participants who were not in a position to mention any strategies leading to an improvement of their writing ability was still lower than before the treatment ( $31 \%$ vs. $52 \%$ ), it actually increased by $11 \%$ in comparison with the situation after the first training session ( $20 \%$ vs. $31 \%)$. Also, fewer students said that they tried to write a lot in English - 18\% vs. $26 \%$. Three strategies remained at the same, or almost the same, level - using a dictionary (6\%), asking other people for help (6\%), and learning new words and expressions (15\%). There were more instances of writing based on a model text (18\% vs. $12 \%$ ), and, additionally, a new strategy - planning what to write (a meta-cognitive strategy) - was mentioned by $6 \%$ of the respondents. However, there was no reference to self-correcting or replacing unknown words with familiar ones, which accounted, respectively, for $12 \%$ and $2 \%$ of the total strategy use as declared by the respondents after the first training session.

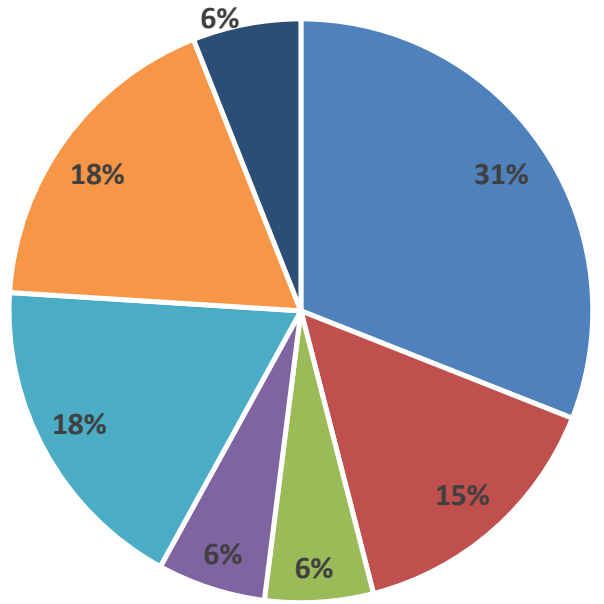

- Lack of strategies

- Learning new words and expressions

- Using a dictionary

- Asking other people for help

- Writing based on a model text

- Trying to write a lot in English

- Planning what to write

Fig. 3: Strategies reported by the students after two training sessions, at the end of the project. 
All in all, the number and the range of strategies reported by the participants were rather limited, although, undoubtedly, some positive changes have to be acknowledged in the students' declared 'strategic behavior' between the beginning of the project and the period after the first training session (cf. Fig. 1 and Fig. 2). Trying to account for what happened, we may assume that the students - 'poor language learners' - as a result of strategy training and the remedial treatment provided by teacher trainees, suddenly discovered that there were ways which can help them achieve better grades, and, perhaps, develop higher proficiency in English - something that we could colloquially call the "wow!" effect. Having become aware of their own strengths and weaknesses and having discovered their own learning styles, many of the students found themselves equipped with tools to make their learning more efficient. What is more, they could have recognized the value of writing, not only as a support for their learning, but also as a way of communicating their thoughts and feelings to others. The very fact of becoming familiar with a number of writing strategies seemed to have offered a welcome solution to their problems with writing in English, and the process of learning English as such. No wonder that a change in their attitude towards English and learning writing (as measured by positive assessment of their efforts by their teachers) contributed to an increase in their level of motivation and confidence, which, unfortunately, did not last throughout the whole course of the project, as seen when we compare the results obtained after the first and the second strategy training sessions.

The decrease in the reported strategy use after the second strategy training session may be attributed to the fact that students (who are poor language learners) realized that the whole process of learning to write is much more complex, requiring not only a lot of time and effort but also knowing the right ways to deal with the problem. Likewise, it is quite plausible that the students, having high hopes after their initial positive encounter with learning strategies, became disappointed with the overall results, which in turn resulted in discouragement, and again, a "change of heart". Another possible explanation is that signs of fatigue and weariness appeared due to the length of the project and, which seems even more significant, the long intervals between the strategy training sessions.

It can be assumed that poor language learners, especially those at a risk of educational failure, find it difficult to improve their learning skills and habits, due to a whole variety of individual and contextual factors, some of which were discussed in the theoretical part of the article. It would be unrealistic to expect quick or radical changes, especially as these students lag behind their more able peers as far as their overall school achievements are concerned. 
Looking at the strategies reported by the students before the onset of the treatment and after the first strategy training session, it seems necessary to comment on the two labelled using a dictionary and using additional materials to find relevant/needed vocabulary, especially as there is no mention of the latter later on. It is actually quite possible that by using additional materials the students also meant consulting a dictionary which somewhat complicates the issue. It comes as a surprise that this particular strategy lost popularity with the respondents and that its use decreased after the two training sessions. Among the most popular strategies, probably found useful by the participants, were: writing based on a model text (a safe and reliable strategy) and trying to write a lot. It also seems that the students realized the value of learning new words and expressions both for the process of writing and for learning the language in general.

To become fully aware of the difficulties experienced by poor language learners in overcoming problems related to learning to write, it might be useful at this point to compare strategies deployed to develop the writing skill as reported by more able students with those listed by learners who took part in the remedial treatment. The data obtained from the students who did not take part in the project (42 in number) are presented in Figure 4 below.

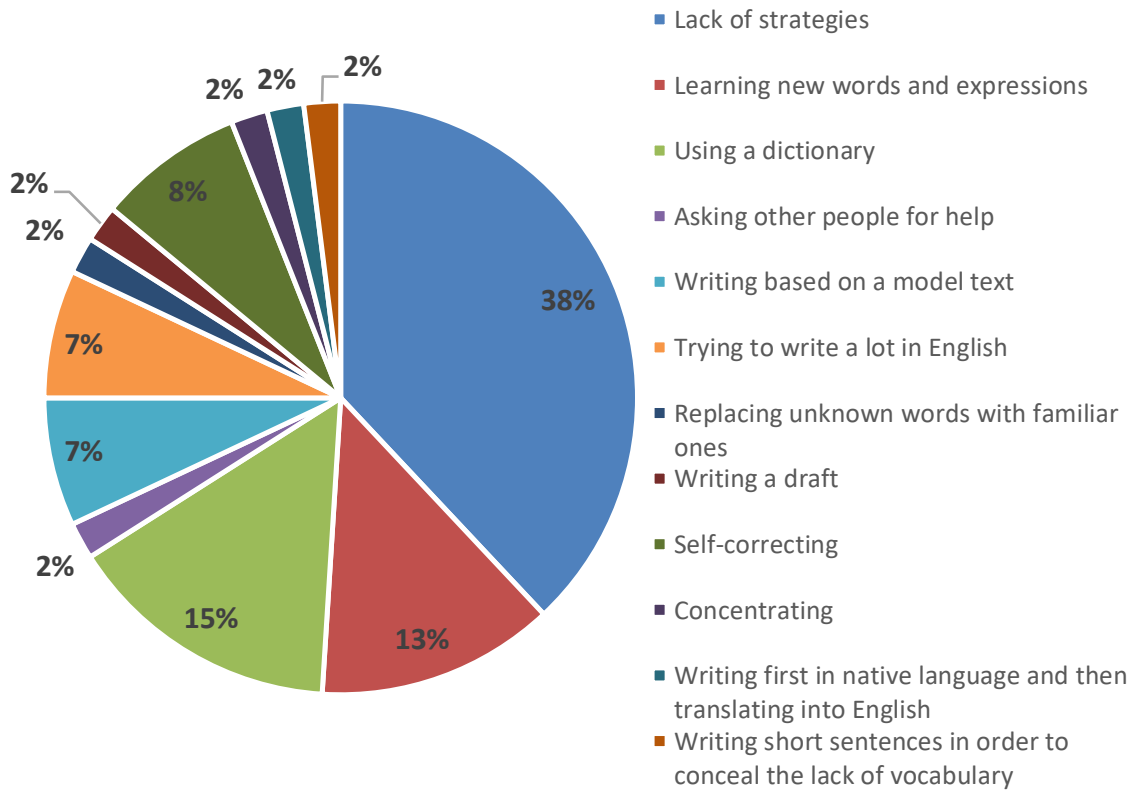

Fig. 4: Strategies deployed to improve the writing skill in English as reported by students who did not take part in the project (at the onset of the project). 
Even though quite a large percentage of "regular" students either did not know any strategies or were not able to verbalise their knowledge (38\%), the remainder reported quite a range of strategies, with self-correcting $(15 \%)$ and learning new words and expressions (13\%) being the most frequently mentioned. Other strategies reported by the learners included using a dictionary (8\%), writing based on a model text (7\%), trying to write a lot in English (7\%), as well as instances of concentrating, replacing unknown words with familiar ones, writing a draft, asking other people for help, writing first in the native language and then translating into English ${ }^{5}$, and writing short sentences in order to conceal the lack of vocabulary ( $2 \%$ each). It does not mean, however, that the strategies reported by the students are effective or that the students who reported using them could be labelled "good language learners" or "good writers". It simply means that they did not experience (or did not report) any serious problems either with learning English in general or with writing in English. Among the strategies mentioned by the students are meta-cognitive and socio-affective ones, however, it is cognitive strategies, i.e. working directly with/on the target language material, that constitute the majority. It has to be kept in mind, however, that altogether the students represented a rather low level of language proficiency, and that actually most of them were at the beginning of their adventure with English, which may account for lack of more complex strategies.

\section{Conclusions, pedagogical implications and suggestions for further research}

Bearing in mind the informal nature of the project, the number of participants and the context in which it took place, any conclusions must be tentative, even though the results obtained are consistent with those from other studies.

The most important conclusion is that strategy training, or strategybased instruction, appeared to benefit these students, who have problems with school education. However, teachers should be cognizant of the fact that the reasons why their students fail are many and varied, and, hence, all learners, especially poor language learners should be taught how to develop/improve their study and language skills with the use of appropriate strategies. First and foremost, though, students must realize the value of learning a foreign language and the role of writing in this process. They must want to learn, i.e. to be willing to devote time and effort to the process of language learning.

\footnotetext{
${ }^{5}$ In terms of strategy use, L1 is believed to serve as an important problem-solving resource used, for instance, to plan the content and organization, to monitor, to translate, etc. (cf. Bloom, 2008: 112).
} 
In the same vein, both teachers and students need to realise that simply knowing about strategies (i.e. strategic knowledge) does not automatically translate into better results - that is higher language proficiency and better control over language skills, including the ability to write in English. However, such knowledge may boost the students' confidence and, as a result, their motivation and willingness to make the effort to learn.

It goes without saying that poor language learners, who are underachievers, need more attention, help and guidance from their teachers. Writing is the skill that requires particular efforts, as it has to be developed in a deliberate, systematic way, even in one's native language. Poor writers get easily discouraged and they quickly lose interest and motivation.

Having metacognitive knowledge, i.e. knowing how to learn, does not mean learners can make use of the knowledge in practice; the very fact of being aware of learning strategies, and even having practised some of them in the course of a language lesson, does not imply that students will automatically start studying in order to improve their level of attainment. Translating declarative knowledge into procedural knowledge is a matter of practice and it takes time. In this particular instance, only a few students who took part in the remedial teaching, including strategy training sessions, managed to improve their final grades, which is, on the whole, disappointing. The reasons for such a state of affairs might lie in the affective domain and, hence, in the lack of affective strategies to deal with stress and anxiety.

The quantity and quality of strategies deployed by the students changed as not all strategies may be considered equally important. As the data demonstrate, poor language learners, if they use any strategies, rely mainly on cognitive rather than meta-cognitive or socio-affective strategies. It is worth noting, though, that even students who did not take part in the project, hardly ever mentioned strategies which could be classified as metacognitive. A possible explanation may be that, perhaps, cognitive strategies are more learnable or easier to develop in the course of lessons, for instance through modelling and/or imitation, which may not work in the case of poor learners. When it comes to meta-cognitive strategies, which are considered more important from the point of view of directing or regulating one's own learning, it becomes clear that they require explicit teaching and a lot of conscious practice. The same concerns socio-affective strategies, whose role in the process of learning is still undervalued by teachers and their students alike.

Researchers tend to agree that it is motivation that is a major factor in the process and that teachers need to attend to motivational levels of their learners so that they will be willing to invest the time and effort which is required for success. That is why learner attitudes should be given due attention 
and attempts to change them undertaken when necessary. The learners need to be convinced that what they are doing is, first of all, worth doing and that they are able to deal with the tasks successfully. Thus, as far as writing is concerned, they need to believe that it is something that will help them in their learning process and that is why it is worth learning to write or developing writing in the foreign language, even though the process itself involves a lot of time and effort and deployment of a lot of conscious strategies.

As far as the length of strategy training is concerned, the results of the present study, contrary to previous findings, seem to suggest that "longer" does not necessarily mean more effective. It seems that in the case of poor language learners strategy training conducted over a longer period of time, with long intervals between the actual training sessions, may not be as effective as a more "compact" course. The students, not being able to notice immediate results of their attempted strategy use, seem to lose interest in learning to write on the one hand, and in learning English on the other.

Finally, poor language learners are not necessarily those who do not want to learn; sometimes they are not given a chance to show what they are able to do, especially in a regular school class where they have to compete with more able peers. As Gordon (2008: 251) observes, “(...) less able students may perceive an opportunity to learn as more valuable and therefore apply themselves to the task of learning with greater urgency". A quote from a diary of one of the teacher-trainees involved in the project may serve as evidence here:

"Pupils were working during my lessons really hard and it was difficult to believe that I was teaching a low attainment group, pupils who have problems with English. It is true that they often lacked some knowledge, but when provided with suitable conditions, they were catching up and I was really surprised with their creativity. Everything they needed was a bit of motivation and individual approach to each of them" (original wording).

Summing up, strategy based instruction should become an inseparable part of the general school curriculum, as learning to learn and use of adequate study skills is simply indispensable. Equipped with the knowledge and experience coming from such instruction, language learners, and hence writers, are not only capable of better understanding both their learning and the process of writing, but can also take control, thus becoming better, more successful language learners. In learning to write, recognizing that writing is a process is the first big step. This process begins with being able to understand the assignment, and ends when the student reads the teacher's comments. However, as Miller notes (1996: 19), there are a number of important steps in between, 
constituting a kind of a programme which good writers follow in a systematic way, often repeating the steps. These can constitute checklist for the teacher and guide him/her in developing writing in the foreign language classroom.

As far as suggestions for future research are concerned, it goes without saying that more studies are needed to obtain a better understanding of how language learners develop and use strategies. With reference to descriptive studies, the field can still benefit from research describing students' current strategies, comparing strategies used by more and less effective learners in different learning contexts, as well as investigating how strategies are developed over time. More experimental, intervention studies are needed examining the effects of strategy based instruction in different age groups. The review of the literature on the subject reveals, for instance, that most of the research has been conducted with high school and college students, whereas data concerning younger learners are still scant.

\section{BIBLIOGRAPHY}

Anderson, N.J. 2008. "Metacognition and good language learners". (in) Lessons from Good Language Learners. (ed. Griffiths, C.). Cambridge: Cambridge University Press: 99-109.

Bloom, M. 2008. "Second language composition in independent settings: supporting the writing process with cognitive strategies". (in) Language Learning Strategies in Independent Settings. (eds. Hurd, S. and Lewis, T.). Bristol: Multilingual Matters: 103- 118.

Chamot, A.U. 2001. "The role of learning strategies in second language acquisition". (in) Learner Contributions to Language Learning (ed. Breen, M.P.). Harlow: Pearson Education: 25-43.

Cohen, A.D. 2011. Strategies in Learning and Using a Second Language. Harlow: Pearson Education.

Cohen, A.D. and Macaro, E. (eds.). 2007. Language Learner Strategies. Oxford: Oxford University Press.

Cottrell, S. 2001. Teaching Study Skills and Supporting Learning. London: Palgrave.

Griffiths, C. (ed.). 2008. Lessons from Good Language Learners. Cambridge: Cambridge University Press.

Griffiths, C. 2013. The Strategy Factor in Successful Language Learning. Bristol: Multilingual Matters.

Ellis, G. and Sinclair, B. 1989. Learning to Learn English. A Course in Learner Training. Cambridge: Cambridge University Press.

Gordon, L. 2008. "Writing and good language learners". (in) Lessons from Good Language Learners (ed. Griffiths, C.). Cambridge: Cambridge University Press: 244-254.

Harmer, J. 1998. How to Teach English. Harlow: Addison Wesley Longman. 
Developing writing strategies of poor language learners at the level of...

Manchón, R.M., de Larios, J.R. and Murphy, L. 2007. “A review of writing strategies: focus on conceptualizations and impact of first language". (in) Language Learner Strategies (eds. Cohen, A.D. and Macaro, E.). Oxford: Oxford University Press: 229-250.

Miller, S. 1996. "Introducing study skills". English Teaching Professional, October 1996, Issue One: 19, 28.

Neuburg, R. and Harris, V. 2003. Jak się uczysz. Przewodnik dla uczq̨cego się języka obcego. Kaunas: Technologija.

Neuburg, R. and Harris, V. 2003. Learning My Way. A Handbook on Language Learning Strategies. Kaunas: Technologija.

O'Malley, J.M. and Chamot, A.U. 1990. Learning Strategies in Second Language Acquisition. Cambridge/New York: Cambridge University Press.

Oxford, R. 2008. "Hero with a thousand faces: learner autonomy, learning strategies and learning tactics in independent language learning". (in) Language Learning Strategies in Independent Settings (red. Hurd, S. and Lewis, T.). Bristol: Multilingual Matters: 41-63.

Rubin, J. and Thompson, I. 1994. How To Be a More Successful Language Learner. Boston: Heinle \& Heinle.

Vann, R.J. and Abraham, R.G. 1990. "Strategies of unsuccessful language learners". TESOL Quarterly 24/2: 177-98.

Wenden, A. 1991. Learner Strategies for Learner Autonomy. London: Prentice Hall.

Wenden, A. 2001. "Metacognitive knowledge in SLA: the neglected variable". (in) Learner Contributions to Language Learning (ed. Breen, M.P.). Harlow: Pearson Education Limited: 44-64. 